J. Lake Sci.(湖泊科学), 2019, 31(2): 407-415

DOI 10. 18307/2019. 0210

(c) 2019 by Journal of Lake Sciences

\title{
贵州草海不同水位梯度下沉积物氮赋存形态及分布特征
}

\author{
吴胜利 ${ }^{1,2}$, 夏品华 ${ }^{1,2 * *}$, 林 陶 ${ }^{1,2}$,杨 杰 $^{1,2}$, 王汝斌 ${ }^{3}$, 陈彦明 ${ }^{3}$ \\ ( 1 : 贵州师范大学贵州省山地环境信息系统与生态环境保护重点实验室,贵阳 550001) \\ ( 2 : 贵州师范大学高原湿地生态与环境研究中心, 贵阳 550001) \\ (3: 贵州草海国家级自然保护区管理委员会,威宁 553100)
}

\begin{abstract}
摘 要: 利用分级浸取分离法, 分析贵州草海湿地沉积物总氮 (TN) 与可转化态氮 ( TF-N) 含量及分布特征, 试图揭示水位 抬升对草海湿地沉积物氮潜在释放风险的影响. 结果表明, 草海湿地沉积物 TN 含量在 $1.94 \sim 14.07 \mathrm{~g} / \mathrm{kg}$ 之间, 均值为 $7.76 \mathrm{~g} / \mathrm{kg}$; TF-N 含量较高, 在 $1.70 \sim 7.59 \mathrm{~g} / \mathrm{kg}$ 之间, 占 TN 的 $68.7 \%$; 不同形态氮含量依次为有机态及硫化物结合态氮 $(\mathrm{OSF}-\mathrm{N})>$ 离子交换态氮 $($ IEF-N $)>$ 铁锰氧化态氮 $($ IMOF-N $)>$ 弱酸可浸取态氮 (WAEF-N) ; 不同水位梯度下各形态氮含量 变化规律不同, OSF-N、IMOF-N 含量沿着水位升高呈逐渐增加趋势, IEF-N 含量呈先增加后降低的趋势, WAEF-N 含量变 化不大; TN 和总非可转化态氮 (NTF-N) 与有机质 (SOM) 含量之间呈显著正相关, 可能具有相似的来源. 总之, 草海沉积 物 TF-N 含量及比例较高, 潜在释放风险较大, 而水位抬升抑制氮的转化, 促进沉积物氮积累, 增加释放风险. 该研究揭示 了不同水位梯度下沉积物氮形态分布特征, 丰富了水文条件对氮迁移转化影响的理解, 为湿地生态补水工程的管理决策 提供了科学依据.
\end{abstract}

关键词: 草海;湿地; 水位梯度;氮素形态; 释放风险

\section{Contents and distribution characteristics of nitrogen forms in sediments of Guizhou Lake Caohai under different water level levels}

\author{
WU Shengli ${ }^{1,2}$, XIA Pinhua ${ }^{1,2 * *}$, LIN Tao ${ }^{1,2}$, YANG Jie ${ }^{1,2}$, WANG Rubin ${ }^{3}$ \& CHEN Yanming ${ }^{3}$ \\ (1: Key Laboratory for Information System of Mountainous Areas and Protection of Ecological Environment of Guizhou Prov- \\ ince, Guiyang 550001, P.R.China) \\ (2: Plateau Wetland Ecology and Environment Research Center, Guizhou Normal University, Guiyang 550001, P.R.China) \\ (3: Guizhou Caohai National Nature Reserve Management Committee, Weining 553100, P.R. China)
}

Abstract: Lake Caohai situated in Guizhou Province is a plateau lake. The contents and distribution characteristics of total nitrogen (TN) and transferable nitrogen ( TF-N) in sediments of Lake Caohai wetland were analyzed by using the method of fractional leaching and separation, and the effect of water level uplift on the potential nitrogen release risk of sediments was revealed. The results showed that the TN content in sediments ranged from 1.94 to $14.07 \mathrm{~g} / \mathrm{kg}$, with an average of $7.76 \mathrm{~g} / \mathrm{kg}$. The content of TF-N was relatively higher ( between 1.70 and $7.59 \mathrm{~g} / \mathrm{kg}$ ), accounting for $68.7 \%$ of TN. Nitrogen content of transformable nitrogen in different forms was organic matter-sulfide form nitrogen ( OSF-N) > ion-extractable form nitrogen ( IEF-N) > iron-manganese oxides form nitrogen $($ IMOF-N $)>$ weak acid extractable form nitrogen ( WAEF-N). Under different water level, the changeable regulation of transformable nitrogen content of each form was different. OSF-N and IMOF-N increased gradually along the water level, while IEF-N first increased and then decreased. WAEF-N did not change much. There was a significant positive correlation between TN and non-transferable nitrogen ( NTF-N) and soil organic matter ( SOM), which may have similar sources. Shortly, Lake Caohai sediments have higher levels of transformable nitrogen and higher risk of potential release, while elevated water levels increase the risk of nitrogen release. The study reveals the nitrogen distribution characteristics of sediments under different water level, enriches

* 国家自然科学基金项目 (41867056)、贵州省重大科技专项（20163022-2）、贵州师范大学博士科研启动项目、贵州 省林业科研项目 ( [2014] 11 号) 和贵州省科技合作计划资助项目 (20167200) 联合资助. 2018-07-07 收稿; 201809-05 收修改稿. 吴胜利 (1993 ), 男, 硕士研究生; E-mail: 792845329@ qq.com.

** 通信作者;E-mail:pinhuayy@163.com. 
the understanding of the impact of hydrological conditions on the migration and transformation of nitrogen, and provides a scientific basis for management decision of wetland ecological replenishment projects.

Keywords: Lake Caohai; wetland; water level; nitrogen form; release risk

氮作为地表系统中主要营养元素之一, 被认为是湿地等水生生态系统初级生产力的关键限制性因子 ${ }^{[1]}$. 沉积物作为湿地生态系统中氮的重要源和汇, 对水环境质量有着重要的影响. 沉积物中氮分为可转化态氮 (Transferable nitrogen, TF-N) 和非可转化态氮 ( Non-transferable nitrogen, NTF-N), 其中 TF-N 由离子交换态氮 (Ion-extractable form nitrogen, IEF-N)、弱酸可提取态氮 (Weak acid extractable form nitrogen, WAEF-N)、铁锰氧 化态氮 ( Iron-manganese oxides form nitrogen, IMOF-N) 以及有机态和硫化物结合态氮 ( organic matter-sulfide form nitrogen, OSF-N ) 4 种形态组成 ${ }^{[2]}$. 据研究, 沉积物中不同形态氮的环境地球化学行为存在差异 ${ }^{[3]}$, 并不是所 有的氮都能直接释放而进人上覆水, 只有 “活跃” 的氮组分才能在沉积物一水界面发生迁移和转化 ${ }^{[4-5]}$. 沉积 物中最容易释放到水体中的氮形态为可交换态氮 (Exchangeable nitrogen, EN), 在水一沉积物界面氮交换过 程中起着关键性作用 ${ }^{[6]}$. 对沉积物中氮赋存形态与分布特征的研究, 是准确理解湿地生态系统中氮的生物 地球化学循环作用以及环境效应的基础.

沉积物中氮赋存形态备受关注, 王圣瑞等 ${ }^{[7]}$ 采用分级浸取分离的方法, 对长江中下游地区 14 个浅水型 湖泊沉积物中的氮形态及释放特征进行了探讨. 在沉积物氮赋存形态及时空分布 ${ }^{[8-9]}$ 、生物有效性 ${ }^{[10]}$ 、潜在 释放风险 ${ }^{[11]}$ 及生态效应 ${ }^{[12]}$ 等方面有了不少的报道, 但是水文条件对氮赋存形态影响的研究较为鿒乏. 水文 条件是湿地的根本属性, 是控制湿地生物地球化学循环的关键因子. 在全球变化的背景下, 由于人类活动的 影响,湿地水文条件发生了巨大的变化. 水位升高或降低, 对沉积物理化特性、氧化还原特性和植物群落产 生显著影响, 这些变化也会对湿地沉积物氮素的生物地球化学循环产生影响, 但是, 湿地不同水位梯度下沉 积物氮赋存形态及分布尚不清楚.

草海是贵州省最大的天然湖泊湿地, 早在 1992 年就被列为国家级自然保护区, 是一个完整的、典型的 高原湿地生态系统, 其也是中国特有高原鹤类黑颈鹤的主要越冬地之一 ${ }^{[13]}$. 草海湿地历经沧桑, 过去遭受 大规模排干, 水域面积减小, 近年又受到污染, 水体富营养化日益严重 ${ }^{[14]}$. 为了恢复草海生态, 有关部门提 出调水补水和建设出水闸抬升水位等措施. 这些措施有利于湿地面积恢复,但淹没农田、改变水文条件影响 氮磷赋存与行为, 可能影响水环境质量而备受争议. 为此, 本文使用分级浸取分离的方法, 研究草海湿地不 同水位梯度下沉积物氮赋存形态, 以及各形态间和沉积物理化因子之间的关系, 揭示水文条件对沉积物氮 素形态分布的影响, 以期为草海湿地抬升水位恢复湿地管理决策提供参考依据.

\section{1 材料与方法}

\section{1 研究区域}

草海湿地位于云贵高原中部的乌蒙山山麓腹地, 贵州省西部威宁彝族回族苗族自治县, 是贵州省内最 大的天然淡水湖泊, 中国三大高原湖泊之一, 为国家 I 级重要湿地 ${ }^{[15]}$. 根据草海湿地土地利用情况, 沿湖岸 至湖心的截面设 4 个采样点, 标记为 $\mathrm{CH} 1 \sim \mathrm{CH} 4$ (图 1). 截面按照 $\mathrm{Wetze}^{[16]}$ 的湖泊沼泽学分类, 剖面可以分 为 3 个子区域: 水位变幅区 (湖岸带)、水向辐射区 (过渡带) 和开阔水体 (湖心).

\section{2 沉积物样品的采集与制备}

于 2016 年 8 月上旬采集沉积物样品. 在每个断面随机选择 3 个 $1.0 \mathrm{~m} \times 1.0 \mathrm{~m}$ 样地, 共计 12 个样方, 每 个样地采集 3 个重复沉积物样品, 采集途中将 3 个重复沉积物样品尽可能完全混合均匀. 取样时先将沉积 物表层植物调落物以及植被去除, 然后用柱状采样器采集沉积物深度为 $0 \sim 10 \mathrm{~cm}$, 混合好的沉积物立即放人 自封袋进行密封, 快速运回实验室. 在实验室中剔除植物须根以及其他残体, 然后将其分为两份, 一份于 $4^{\circ} \mathrm{C}$ 冰箱保存备用; 另一份放置风干盘中自然风干, 适时压碎研磨, 过 100 目土壤篮, 混合均匀放置自封袋中用 于测定形态氮及相关理化指标 ${ }^{[17]}$.

\section{3 分析方法}

沉积物氮形态测定采用马红波等 ${ }^{[18]}$ 分级浸取分离的方法. 分别用 $1 \mathrm{~mol} / \mathrm{L}$ 氯化钾 $(\mathrm{KCl})$ 溶液、 $\mathrm{pH}=5$ 的 


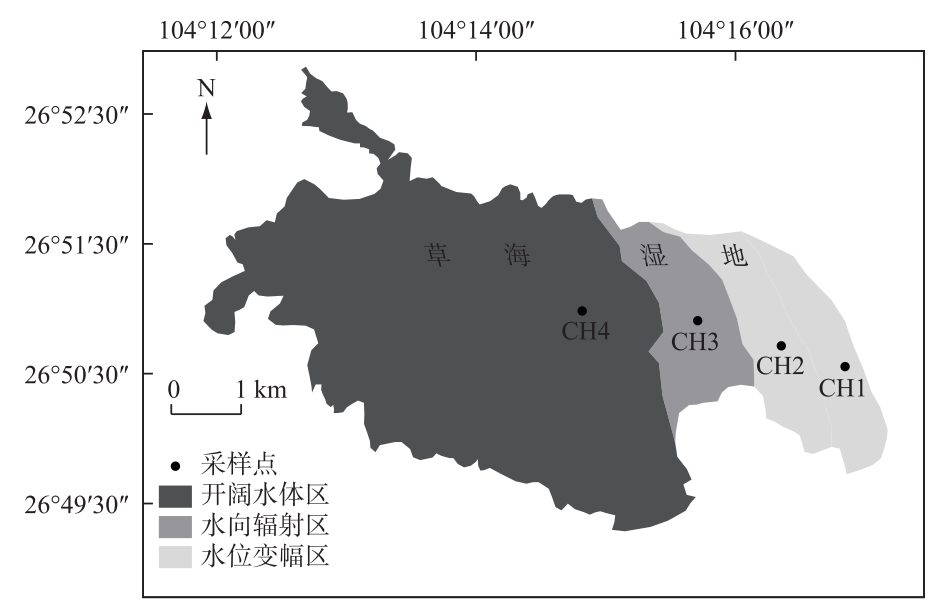

图 1 草海采样点地理位置

Fig.1 Geographic location of sampling sites in Lake Caohai

醋酸一醋酸钠 $(\mathrm{HAC}-\mathrm{NaAC}$ ) 溶液、 $0.1 \mathrm{~mol} / \mathrm{L}$ 氢氧化钠 $(\mathrm{NaOH})$ 溶液以及 $0.24 \mathrm{~mol} / \mathrm{L} \mathrm{NaOH}$ 溶液 $/ 0.074 \mathrm{~mol} / \mathrm{L}$ 过硫酸钾 $\left(\mathrm{K}_{2} \mathrm{~S}_{2} \mathrm{O}_{8}\right)$ 溶液对样品进行提取. 沉积物总氮 ( TN ) 含量使用凯氏定氮法测定, 浸取液中铵态氮 $\left(\mathrm{NH}_{4}^{+}-\mathrm{N}\right)$ 含量采用次溴酸钠氧化法测定、硝态氮 $\left(\mathrm{NO}_{3}^{-}-\mathrm{N}\right)$ 含量采用镀铜镉还原一重氮化偶合比色法测定, 得 到可转化态氮 ( TF-N) 的 4 种形态, 分别为 IEF-N、WAEF-N、IMOF-N 以及 OSF-N, TN 与 TF-N 的差值即为非 可转化态氮 (NTF-N). 沉积物 $\mathrm{pH}$ 采用水土质量比为 $2.5: 1$ 电极法测定; 总磷 ( TP ) 含量采用酸溶一钼锑抗比 色法测定; 有机质 (SOM) 含量采用重铬酸钾容量法一外加热法测定.

\section{4 数据分析与处理}

使用 ArcGis 10.5 软件制作采样示意图; 采用 SPSS 18.0 软件进行 ANOVA 显著性检验和相关性分析; 利 用 Origin 9.0 软件作图.

\section{2 结果与讨论}

\section{1 沉积物基本理化特征}

沉积物理化性质是氮形态的重要影响因素, 贵州草海从水位变幅区至开阔水体区的 $\mathrm{pH}$ 变化范围为 6.29 7.72, 整体上处于中性偏弱碱性范围; 含水率变化范围为 $62.11 \% \sim 323.29 \%$; TP 含量为 $0.200 \sim 0.347 \mathrm{~g} /$ $\mathrm{kg}$, 均值为 $0.274 \mathrm{~g} / \mathrm{kg}$, 其最高值出现在 CH4 处, 即开阔水体处; 最低值出现在 $\mathrm{CH} 2$, 即水位变幅区; SOM 含 量范围为 $26.7 \sim 290.65 \mathrm{~g} / \mathrm{kg}$, 最高值出现在开阔水体, 最低值出现在 $\mathrm{CH} 2$ 处, 即水位变幅区, 空间分布不均 匀(表 1 ).

表 1 沉积物基本理化指标 ${ }^{*}$

Tab.1 Physical and chemical properties of the sediments

\begin{tabular}{crrrrr}
\hline 采样点 & $\mathrm{SOM} /(\mathrm{g} / \mathrm{kg})$ & $\mathrm{TP} /(\mathrm{g} / \mathrm{kg})$ & 含水率 $/ \%$ & $\mathrm{pH}$ & 水深 $/ \mathrm{cm}$ \\
\hline $\mathrm{CH} 1$ & $43.02 \pm 6.05^{\mathrm{a}}$ & $0.26 \pm 0.025^{\mathrm{a}}$ & $67.79 \pm 1.33^{\mathrm{a}}$ & $7.41 \pm 0.32^{\mathrm{a}}$ & $24 \pm 2^{\mathrm{a}}$ \\
$\mathrm{CH} 2$ & $28.82 \pm 2.12^{\mathrm{a}}$ & $0.20 \pm 0.003^{\mathrm{b}}$ & $63.36 \pm 1.25^{\mathrm{a}}$ & $7.68 \pm 0.04^{\mathrm{a}}$ & $52 \pm 2^{\mathrm{b}}$ \\
$\mathrm{CH} 3$ & $139.8 \pm 12.05^{\mathrm{b}}$ & $0.23 \pm 0.031^{\mathrm{a}}$ & $97.48 \pm 2.35^{\mathrm{b}}$ & $6.61 \pm 0.32^{\mathrm{b}}$ & $83 \pm 3^{\mathrm{c}}$ \\
$\mathrm{CH} 4$ & $259.4 \pm 31.25^{\mathrm{c}}$ & $0.32 \pm 0.031^{\mathrm{c}}$ & $317.67 \pm 5.62^{\mathrm{c}}$ & $7.32 \pm 0.05^{\mathrm{c}}$ & $176 \pm 3^{\mathrm{d}}$ \\
\hline
\end{tabular}

* 沉积物理化指标数值为平均值 \pm 标准偏差 $(n=3)$, 同一列上标不同小写字母表示处理在 $P \leqslant 0.05$ 水平差异显著.

\section{2 沉积物 TN、TF-N 及 NTF-N 含量及分布}

草海沉积物 TN 含量在 $1.94 \sim 13.59 \mathrm{~g} / \mathrm{kg}$ 之间, 平均值为 $7.76 \mathrm{~g} / \mathrm{kg}$. TN 作为反映沉积物营养水平的一个重 
要指标, 由可转化态氮 (TF-N) 和非可转化态氮 (NTF-N) 组成. 由于氮较高的迁移性和生物可利用性, 草海湖滨 CH1 和 CH2 要远远低于宽敞水域 CH3 和 CH4, 表明深水环境有利 TN 的累积. 这与杨海全等 ${ }^{[19]}$ 草海沉积物 $\mathrm{TN}$ 含量呈湖心高、近岸低的研究结果一致. CH3 和 $\mathrm{CH} 4$ 样点水位相对较高, 沉水植被生长茂盛, 吸收水体和沉 积物中的氮素, 大量植物枯萎后又返还到沉积物. 草海沉积物 TN 含量明显受湖泊水生植物生长控制, 主要以 有机质形式赋存于沉积物中 ${ }^{[19]}$. 湖滨 $\mathrm{CH} 1$ 和 $\mathrm{CH} 2$ 较低的 TN 含量, 可能还与其周期性淹水/落干的水文条件 有关.

草海 TF-N 含量及占 TN 比例较高, 氮潜在释放风险较大. TF- $\mathrm{N}$ 含量变化范围为 $1.70 \sim 7.59 \mathrm{~g} / \mathrm{kg}$, 均值为 $4.65 \mathrm{~g} / \mathrm{kg}$; 占 TN 百分比为 $55.8 \% \sim 87.6 \%$, 平均为 $68.7 \%$. TF-N 含量最高值出现在湖心开阔水体 CH4 处; 最 低值出现在水位变幅区 $\mathrm{CH} 2$ 处. TF-N 和 TN 含量的分布特征一致,即开阔水体高, 湖滨水位变幅区低. TF-N 作为易释放的一类氮素形态, 在 TN 中所占的比例较高, 在适宜的环境条件下会成为水体的二次污染源, 其 对湖泊水体造成富营养化的潜在影响不可忽视. 草海沉积物 NTF-N 含量为 $0.24 \sim 6.00 \mathrm{~g} / \mathrm{kg}$, 均值为 $3.12 \mathrm{~g} /$ $\mathrm{kg}$, 占 TN 百分比为 $12.4 \% \sim 44.2 \%$, 平均为 31.3\% (图 2). 草海沉积物中 TF-N 含量高于 NTF-N, 草海流域主 要是农业种植区, 且草海湖区有着丰富的水生植物和藻类, 其一方面是农业面源污染, 另一方面为植物的调 零, 使 TF-N 含量高于 NTF- ${ }^{[20]}$. 沿水位梯度增加 TF-N 和 NTF-N 含量均在增大, 但 NTF-N 在 TN 中的比例 增大,表明随着水位增大沉积物中的氮趋向于稳定性强的形态发展.
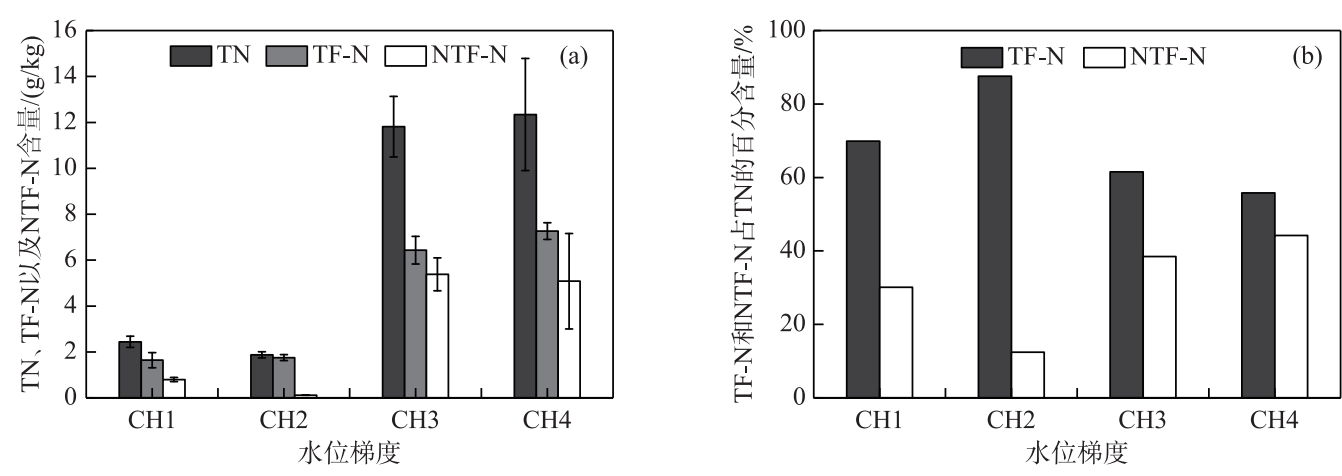

图 2 不同水位梯度下 TN 、TF-N 和 NTF-N 绝对含量以及 TF-N 和 NTF-N 百分含量

Fig.2 Absolute content of TN, TF-N and NTF-N, and percentages of TF-N and NTF-N under different water level gradients

\section{3 可转化态氮的形态与分布}

沉积物 TF-N 由 IEF-N W WAEF-N IMOF-N 和 OSF-N 组成, 其中前 3 种为无机氮, 而 OSF-N 主要为有机形 式的氮. 氮的不同形态反映了土壤与之结合强度以及转化能力. 不同形态的氮素有着不同的形成机制, 在循 环中扮演着不同的角色. 草海湿地不同水位梯度下各形态氮绝对含量以及相对百分含量见图 3 和图 4. 不同 形态可转化态氮含量大小依次为有机态及硫化物结合态氮 $(\mathrm{OSF}-\mathrm{N})>$ 离子交换态氮 $($ IEF-N $)>$ 铁锰氧化态氮 $($ IMOF-N $)>$ 弱酸可浸取态氮 (WAEF-N).

OSF-N 主要是与相对分子质量较稳定的高分子化合物结合的形态氮, 其也被称为强氧化剂可提取态 氮, OSF-N 作为 TF-N 中释放能力最弱的, 其最难以被释放而参与氮循环过程 ${ }^{[20]}$. 草海沉积物 TF-N 中 OSF-N 含量最高, 其在 $1.15 \sim 6.66 \mathrm{~g} / \mathrm{kg}$ 之间变化, 水位变幅区 $\mathrm{CH} 1$ 最低, 开阔水体处 $\mathrm{CH} 4$ 最高. 占 TF-N 可转化态 比例的 $65.96 \% \sim 91.45 \%$, 平均为 $78.71 \%$, 在 TF-N 中占有绝对优势, 其也是 TF- $\mathrm{N}$ 的主要赋存形式 ${ }^{[21]}$. 虽然 OSF $-\mathrm{N}$ 释放能力相对于其他 3 种可转化态氮是最弱的, 但是较高的含量也会增加其释放的风险. 吕晓霞 等 ${ }^{[22]}$ 在研究南黄海表层不同粒级沉积物中氮的地球化学特征表明, OSF-N 含量高的区域,其释放的量也较 高. 草海 OSF-N 含量沿着水位增加逐渐增大, 暗示水位抬升促进 OSF-N 积累, 进而会增加氮的释放风险.

IEF-N 代表一种松散吸附于沉积物阳离子交换位点的水溶性结合态氮, 该类型的氮为不稳定氮, 容易为 植物吸收利用, 是 TF-N 中的 “活跃” 形态, 也是 TF-N 中结合能力最弱的, 为极容易被释放参与水体氮循环的 
形态 ${ }^{[20-21]}$. 草海沉积物 IEF-N 含量较低, 在 $0.29 \sim 0.50 \mathrm{~g} / \mathrm{kg}$ 之间, 均值为 $0.39 \mathrm{~g} / \mathrm{kg}$; 占 TF-N 的比例较小, 为 $4.08 \% \sim 22.43 \%$, 平均为 $13.82 \%$; IEF-N 含量随着水位升高呈先增加后降低的趋势, 最高值 $(0.50 \mathrm{~g} / \mathrm{kg})$ 出现 在水向辐射区 $\mathrm{CH} 3$ 样点, 最低值 $0.29 \mathrm{~g} / \mathrm{kg}$ 出现在开阔水体 CH4 样点. 三峡库区淹没消落区沉积物中 IEF-N 含量也很低, 有可能因为不同形态在长期的淹水状态下向上覆水体的释放程度不同所导致 ${ }^{[7]}$, IEF-N 作为不 同水位梯度下沉积物氮的主要活性组分, 在长期淹水以及稳定状态下易和上覆水发生交换 ${ }^{[22]}$, 这可能是 IEF-N 含量较低的原因. 也有可能是在不同水位梯度下沉积物氮形态发生了变化, 即一种形态的氮在特定条 件下向另一种形态的氮转化.
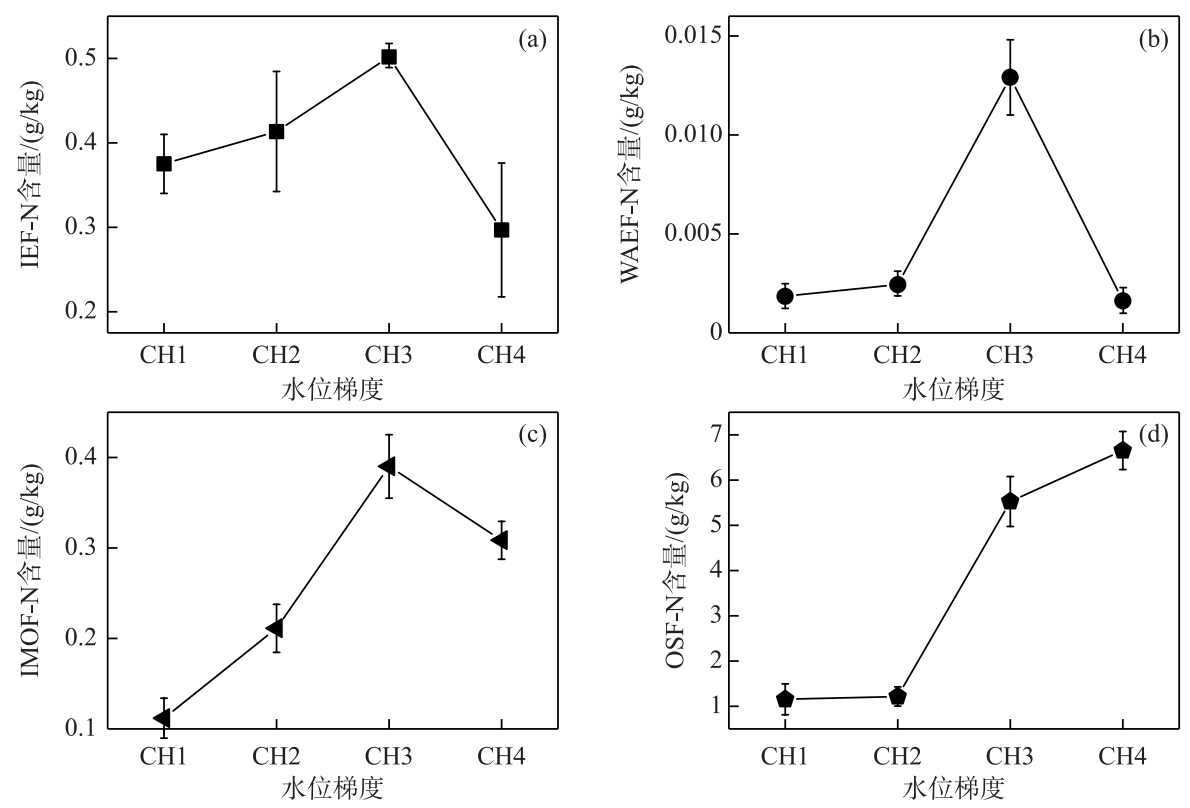

图 3 不同水位梯度下沉积物各形态氮含量 $(\mathrm{EF}-\mathrm{N} 、 \mathrm{WAEF}-\mathrm{N} 、 I M O F-\mathrm{N}$ 及

OSF-N 分别代表离子交换态氮、弱酸可浸取态氮、铁锰氧化态氮和有机态及硫化物结合态氮)

Fig.3 Absolute content of different forms of nitrogen in sediments under different water level gradients

WAEF-N 代表的是弱酸可提取态氮, 其结合能力相 当于碳酸盐的结合能力, 是释放性能略低于 IEF-N 的形 态,其也是一种活性态氮 ${ }^{[22,24]}$. 由图 3 和图 4 可知, 草海 沉积物样品中 WAEF-N 含量最低, 在 $0.0016 \sim 0.0129 \mathrm{~g} /$ $\mathrm{kg}$ 之间, 平均为 $0.0073 \mathrm{~g} / \mathrm{kg}$, 占 TF-N 的比例为 $0.02 \% \sim$ $0.20 \%$, 平均为 $0.11 \%$. 草海不同水位梯度下沉积物中 WAEF-N 含量无明显空间差异 (除 CH3 外). IMOF-N 指 的是铁锰氧化物吸附的氮, 也称为强碱可提取态氮 (SAEF-N), 它的结合能力相当于铁锰氧化物的结合能 力, 略高于 WAEF-N 的结合能力, 故其释放能力低于 WAEF- $\mathrm{N}^{[25-26]}$. 草海沉积物 IMOF-N 含量在 0.13 0.42 g/ $\mathrm{kg}$ 之间,占 TF- $\mathrm{N}$ 的比例为 $4.44 \% \sim 11.49 \%$, 沿着水位增 加逐渐增大, 与鄱阳湖沉积物 IMOF-N 含量分布规律 相似 ${ }^{[26]}$.

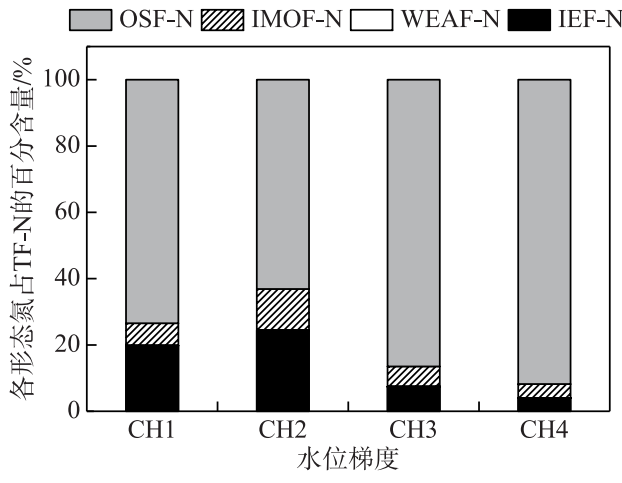

图 4 各形态氮占 TF-N 的百分含量

Fig.4 The percentage of each form of nitrogen in TF-N

水位抬升对氮转化过程的影响也是导致氮素赋存形态变化的重要原因. 氮的循环转化过程包括固氮作 用、硝化作用、反硝化作用和氨化作用,均由微生物驱动 ${ }^{[27-28]}$. 硝化作用包括氨氧化作用和亚硝化作用,氨氧 
化作用主要是一个专性好氧的化能自养过程, 是氮循环的关键性步骤. 氮经矿化或氨化转变成 $\mathrm{NH}_{4}^{+}, \mathrm{NH}_{4}^{+}$易 吸附于土壤中. 在好氧条件下发生 $\mathrm{NH}_{4}^{+}$被氧化为 $\mathrm{NO}_{2}^{-}$, 进一步转化为 $\mathrm{NO}_{3}^{-}$的硝化作用, 硝化作用改变了无机 氮的存在形式, 实现了有机氮的降解. 水位抬升导致缺氧, 限制好氧硝化作用的发生, 促进有机氮的积累, 这 是导致草海 OSF-N 积累的重要因素. 而反硝化作用是一个厌氧过程, 水位抬升为反硝化作用的发生创造了 条件. 脱氮过程所需的硝酸盐主要是沉积物中的氨氮经过硝化作用产生,因水位抬升导致的厌氧环境而受 到限制, 使得沉积物氮的积累. 这是草海沉积物氮含量随水位增加而升高的重要原因. 可见, 水位抬升抑制 氮的转化过程,阻碍湿地生物脱氮, 导致氮积累, 增加了氮潜在释放风险.

\section{4 氮赋存形态与环境因子的关系}

从湖滨水位变幅区至湖心宽敞水域, 植物群落、沉积物理化和生物特性发生显著变化, 这些环境因子的 变化会影响氮形态含量及其分布. 对不同水位梯度下沉积物理化因子 ( SOM、TP、 $\mathrm{pH} 、 \mathrm{MC}$ 以及 WD) 与各形 态氮 ( IEF-N、WAEF-N、IMOF-N、OSF-N、TF-N、NTF-N 以及 TN) 之间进行 Pearson 相关性分析, 结果见表 2.

表 2 不同水位梯度下沉积物样品中不同形态氮含量与理化因子之间的相关性

Tab.2 Correlations between different nitrogen forms and physicochemical properties

in sediment samples under different water level gradients

\begin{tabular}{|c|c|c|c|c|c|c|c|c|c|c|c|}
\hline 相关性 & $\mathrm{TN}$ & IEF-N & WAEF-N & IMOF-N & OSF-N & TF-N & NTF-N & TP & SOM & $\mathrm{pH}$ & MC \\
\hline IEF-N & -0.14 & & & & & & & & & & \\
\hline WAEF-N & 0.41 & 0.84 & & & & & & & & & \\
\hline IMOF-N & 0.84 & 0.37 & 0.76 & & & & & & & & \\
\hline OSF-N & $0.99^{* * *}$ & -0.11 & 0.44 & 0.85 & & & & & & & \\
\hline TF-N & $0.99^{* *}$ & -0.06 & 0.48 & 0.88 & $0.99^{* *}$ & & & & & & \\
\hline NTF-N & $0.99^{* *}$ & -0.23 & 0.33 & 0.78 & $0.99^{* *}$ & $0.98^{*}$ & & & & & \\
\hline TP & 0.58 & -0.81 & -0.39 & 0.03 & 0.55 & 0.51 & 0.65 & & & & \\
\hline SOM & $0.95^{*}$ & -0.43 & 0.11 & 0.66 & 0.94 & 0.93 & $0.97 *$ & 0.75 & & & \\
\hline $\mathrm{pH}$ & -0.63 & -0.60 & -0.93 & -0.79 & -0.65 & -0.68 & -0.57 & 0.04 & -0.37 & & \\
\hline $\mathrm{MC}$ & 0.79 & -0.71 & -0.24 & 0.39 & 0.77 & 0.74 & 0.84 & 0.85 & 0.94 & -0.03 & \\
\hline WD & 0.86 & -0.52 & -0.05 & 0.59 & 0.85 & 0.83 & 0.89 & 0.69 & $0.95^{*}$ & -0.16 & $0.96^{*}$ \\
\hline
\end{tabular}

* 表示显著相关 $P<0.05, * *$ 表示 $P<0.01$ (双尾检验).

从表 2 可以看出, TN 与 OSF-N TF-N 及 NTF-N 含量均呈极显著相关 $(P<0.01)$, 与 IEF-N、WAEF-N 以及 IMOF-N 含量均无显著相关性 $(P>0.05)$, 说明 TF-N、NTF-N、OSF-N 含量变化对 TN 含量影响较大, 而 TN 含 量与 IEF-N、WAEF-N 以及 IMOF-N 含量关系不大. TF-N 与 OSF-N 呈极显著相关 $(P<0.01)$, 与 NTF-N 之间呈 显著性相关 $(P<0.05)$; 在各形态氮中, OSF-N 与 IEF-N、WAEF-N、IMOF-N 相关性均不显著, 这表明沉积物中 OSF-N 与 IEF-N、WAEF-N、IMOF-N 来源可能不同 ${ }^{[8,20]}$.

根据不同水位梯度下沉积物氮形态与其理化特征 ( $\mathrm{SOM} 、 \mathrm{pH} 、 \mathrm{TP} 、 \mathrm{MC}$ 以及 WD) 之间的关系可以推断氮 素形态分布的驱动因子. 不同水位梯度下沉积物 TN 和 NTF-N 与 SOM 之间呈显著正相关 $(P<0.05)$, 说明 TN、NTF-N 与 SOM 可能具有相似的来源或不同水位梯度下沉积物氮形态的分布会受到 SOM 输人的影响. 草海沉积物中 SOM 和 TN 来源一致, 且以有机质形式存在 ${ }^{[29]}$, 草海沉积物中氮受外源污染和初级生产力控 制, 其 $\mathrm{TN}$ 的直接来源中, 藻类以及水生植物所占比重较大, 并且以有机质形式存在 ${ }^{[19]}$. 沉积物中氮形态与 其理化性质 $(\mathrm{pH} 、 \mathrm{MC} 、 \mathrm{TP})$ 不具显著相关性 $(P>0.05)$, 这些因子不是影响氮形态分布的主要因素 ${ }^{[30]}$. 可见, 有机质是影响草海沉积物氮赋存的重要因素, 水位抬升对沉积物有机质的影响, 将会影响到草海沉积物氮 的分布.

\section{5 水位抬升对沉积物氮形态影响的环境意义}

随着水位抬升, 草海沉积物 TN 及 TF-N 含量逐渐增加, 但 TF-N 占 TN 含量的百分比在减少. 这表明虽 然随着水位升高, TN、TF-N 含量都在增加, 但是 TF- $\mathrm{N}$ 对 TN 含量增加的贡献呈减小趋势, $\mathrm{TN}$ 的增加主要来 自 NTF-N 含量的增加. 因为污染程度高的沉积物中氮会逐渐趋向于稳定性强的形态 ${ }^{[26]}$, 这是草海深水环境 
较浅水环境沉积物 NTF-N 高的原因. 深水环境氮的转化受到限制, 短期内无法参与循环的非可转化态氮占 $\mathrm{TN}$ 的比重增大, 即活泼的氮形态逐渐转化成为稳定性较高的形态. 不过, 湿地的水位并不是一成不变的, 具 有明显的水文周期, 低水位时, 沉积物中的氮又因好氧硝化过程加强, 沉积物中稳定性较高的形态氮向活泼 的氮形态转化, 沉积物可转化态氮含量增加, 从而对草海水质产生一定影响, 即在一定程度上增加其富营养 化风险.

抬升水位, 淹没农田中氮的释放也可能对水质产生影响. 草海环湖土地利用基本都是农田,农业生产使 用大量的化肥积累在土壤中, 淹水时可能会向水体迁移而影响水质. 虽然草海抬升水位增加沉积物氮释放 的风险, 但是, 并不等于草海水体氮污染加剧, 因为, 抬升水位的同时也增加了氮的容量. 抬升水位是否加剧 草海水体氮污染取决于氮释放量与容量增加的综合作用.

总之, 水文条件变化导致环境因子的改变影响氮的赋存特征, 随着水位升高, OSF-N 和 IEF-N 含量以及 其占总可转化态氮比例的增幅均较为显著, 氮释放风险增加, 可能会对水质产生深刻影响, 需要做好预案, 防止水质变化. 本文的研究从氮形态分布探讨了氮释放的风险, 但不能反映沉积物中氮对水质的具体影响, 后续还需通过模拟、原位观测等研究,进一步揭示水位抬升的水质响应特征及影响机理.

\section{3 结论}

1) 草海湿地沉积物 TN 含量在 $1.94 \sim 14.07 \mathrm{~g} / \mathrm{kg}$ 之间, 均值为 $7.76 \mathrm{~g} / \mathrm{kg}$; 总可交换态氮含量较高, 在 $1.70 \sim 7.59 \mathrm{~g} / \mathrm{kg}$ 之间, 占 TN 的 $68.7 \%$, 随着水位升高逐渐增大, 较高的可转化态氮含量及比例表明草海沉积 物氮潜在释放风险较大.

2 ) 草海沉积物不同形态可转化态氮含量大小依次为 OSF-N $>$ IEF-N > IMOF-N > WAEF-N, OSF-N IMOF-N 沿着水位升高呈逐渐增加趋势, IEF-N 含量呈先增加后降低的趋势, 而 WAEF-N 含量变化不大, 水位抬升影 响沉积物氮赋存特征,增加沉积物氮释放风险.

3 ) 水位抬升氮释放风险增加, 并不表明草海水体氮污染加剧, 因为草海氮容量也在增加. 后续还需结合 草海水文变化特征,进一步揭示草海生态补水对水环境质量的影响,为草海湿地管理决策提供科学依据.

\section{4 参考文献}

[ 1 ] Nowlin WH, Evarts JL, Vanni MJ. Release rates and potential fates of nitrogen and phosphorus from sediments in a eutrophic reservoir. Freshwater Biology, 2005, 50(2) : 301-322.

[ 2 ] Liu B, Zhou F, Wang GX et al. Research progress on forms of nitrogen and determination in the sediments. Acta Ecologica Sinica, 2011, 31(22): 6947-6958. [ 刘波, 周锋, 王国祥等. 沉积物氮形态与测定方法研究进展. 生态学报, 2011, 31(22): 6947-6958.]

[ 3 ] Lü XX, Song JM, Yuan HM et al. The potential ecological roles of nitrogen in the surface sediments of the South Yellow Sea. Acta Ecologica Sinica , 2004, 24(8)：1635-1642. [吕晓霞, 宋金明, 袁华茂等. 南黄海表层沉积物中氮的潜在 生态学功能. 生态学报, 2004, 24(8): 1635-1642.]

[ 4 ] Han H, Lu X, Burger DF et al. Nitrogen dynamics at the sediment-water interface in a tropical reservoir. Ecological Engineering, 2014, 73: 146-153.

[ 5 ] Ni Z, Wang S. Historical accumulation and environmental risk of nitrogen and phosphorus in sediments of Erhai Lake, Southwest China. Ecological Engineering, 2015, 79: 42-53.

[ 6 ] Wang SH, Jiang X, Zhong LX et al. Seasonal occurrence characteristics of different forms of nitrogen in the sediments of Chaohu Lake. Environmental Science, 2010, 31(4) : 946-953. [王书航, 姜霞, 钟立香等. 巢湖沉积物不同形态氮季 节性赋存特征. 环境科学, 2010, 31(4): 946-953.]

[ 7 ] Wang SR, Jiao LX, Jin XC et al. Distribution of total, exchangeable and fixed nitrogen in the sediments from shallow lakes in the middle and lower reaches of the Yangtze River. Acta Scientiae Circumstantiae, 2008, 28(1): 37-43. [王圣瑞, 焦 立新, 金相灿等. 长江中下游浅水湖泊沉积物总氮、可交换态氮与固定态铵的赋存特征. 环境科学学报, 2008, 28 (1) : 37-43.]

[ 8 ] Zhang L, Qin YW, Zheng BH et al. Nitrogen forms and its distribution character in immerged and water-level- fluctuating zone soils of the backwater reach from input river of Three Gorges Reservoir. Environmental Science, 2009, 30(10) : 2884- 
2890. [张雷, 秦延文, 郑丙辉等. 三峡人库河流大宁河回水区浸没土壤及消落带土壤氮形态及分布特征. 环境科 学, 2009, 30(10): 2884-2890.]

[ 9 ] Wang WW, Wang SH, Jiang X et al. Occurrence characteristics and release risk of nitrogen fractions in sediments of Dongting Lake. Research of Environmental Sciences, 2013, 26(6):598-605. [王雯雯, 王书航, 姜霞等. 洞庭湖沉积物 不同形态氮赋存特征及其释放风险. 环境科学研究, 2013, 26(6) : 598-605.]

[10] Zhao L, Jiang X, Wang WW et al. Occurrence characteristics and bio-availability of nitrogen fractions in sediments of Danjiangkou Reservoir. Resources and Environment in the Yangtze Basin, 2016, 25(4): 630-637. [赵丽, 姜霞, 王雯雯等. 丹江口水库表层沉积物不同形态氮的赋存特征及其生物有效性. 长江流域资源与环境, 2016, 25(4): 630-637.]

[11] Wang WW, Wang SH, Jiang X et al. Occurrence characteristics and release potential of nitrogen fractions in sediment of Lihu Lake. Chinese Journal of Environmental Science, 2017, 37(1):292-301. [王雯雯, 王书航, 姜霞等. 蟙湖沉积物 不同形态氮赋存特征及其释放潜力. 中国环境科学, 2017, 37(1) : 292-301.]

[12] Wang YL, Hu YY, Yang CM et al. Transferable nitrogen forms in sediment from Nanfei River and its impacts on overlaying water quality. Chinese Journal of Environmental Engineering, 2017, 11(9)：5057-5064. [王育来, 胡芸芸, 杨长明等. 南淝河沉积物可转化态氮赋存形态及其对上覆水水质的影响. 环境工程学报, 2017, 11(9): 5057-5064.]

[13] Peng YS, Yang RD. Environmental change of Caohai Lake, Guizhou Province from 730 ka to present and future evolution. Journal of Earth Environment, 2014, 5(3) : 194-206. [彭益书, 杨瑞东. 贵州草海湿地 $730 \mathrm{ka}$ 来的环境变迁及草海 未来的演化分析. 地球环境学报, 2014, 5(3): 194-206.]

[14] Ouyang Y, Lin CH, He TB et al. Study on phytoremediation of eutrophication in Caohai Lake of Guizhou. Guizhou Science, 2011, 29(6) : 21-25. [ 欧阳勇, 林昌虎, 何腾兵等. 贵州草海水体富营养化的植物修复研究. 贵州科学, 2011,29 (6) : 21-25.]

[15] Ran JC, Li GP, Miao QL et al. Grass lake plateau lake wetlands on the roof of Guizhou Province. China Weekly, 2017, (2) : 56-61. [ 再景丞, 李贵平, 苗麒麟等. 草海 贵州屋脊上的高原湖泊湿地. 中国周刊, 2017，(2) : 56-61.]

[16] Wetzel RG. Limonology: Lake and river ecosystem. New York: Elsevier, 2001.

[17] Xia PH, Lin T. Spatial and temporal distributions of the metazooplankton community structure ang water quality in Baihuahu reservoir. Journal of Guizhou Normal University: Natural Science, 2018, 36(1) : 45-50. [夏品华, 林陶. 百花湖水库 后生浮游动物群落结构时空分布特征及水质评价. 贵州师范大学学报: 自然版, 2018, 36(1) : 45-50.]

[18] Ma HB, Song JM, Lv XX et al. Nitrogen forms and their functions in recycling of the Bohai Sea sediments. Geochimica, 2003, 32(1) : 48-54. [ 马红波, 宋金明, 吕晓霞等. 渤海沉积物中氮的形态及其在循环中的作用. 地球化学, 2003, $32(1): 48-54$.]

[19] Yang HQ, Chen JA, Liu W et al. Distribution characteristics and controlling factors of total organic carbon, total nitrogen, and total phosphorus in sediments of Caohai Lake, China. Earth and Environment, 2016, 44(3): 297-303. [杨海全, 陈 敬安, 刘文等. 草海沉积物营养元素分布特征与控制因素. 地球与环境, 2016, 44(3): 297-303.]

[20] Zhang B, Chen YP, Fang F et al. Nitrogen forms and their distribution characteristics in the soils of water-level-fluctuationg zone in the central Three Gorges Reservoir. Acta Scientiae Circumstantiae, 2012, 32(5): 1126-1133. [张涁, 陈奠 鹏, 方芳等. 三峡库区淹没消落区土壤氮素形态及分布特征. 环境科学学报, 2012, 32(5): 1126-1133.]

[21] Zeng YX, Lei P, Zhang H et al. Nitrogen and phosphorus fractions and releasing characteristics of the soils from the representative water-level-fluctuating zone of Danjiangkou Reservoir. Acta Scientiae Circumstantiae, 2015, 35(5) : 1383-1392. [曾祉祥, 雷沛, 张洪等. 丹江口水库典型消落区土壤氮磷赋存形态及释放特征研究. 环境科学学报, 2015,35 (5) : 1383-1392.]

[22] Lv XX, Song JM, Yuan HM et al. Geochemical characteristics of nitrogen in different grain size sediment from the southern Huanghai Sea. Acta Oceanologica Sinica, 2005, 27(1): 64-69. [吕晓霞, 宋金明, 袁华茂等. 南黄海表层不同粒级沉 积物中氮的地球化学特征. 海洋学报, 2005, 27(1): 64-69.]

[23] Wang M, Liu Y, Zheng BH et al. Nitrogen forms in surface sediments of urban river and their influence factors: A case study of Qingyi River in Xuchang City. Chinese Journal of Environmental Science, 2014, 34(3): 720-726. [王梅, 刘琰, 郑丙辉等. 城市内河表层沉积物氮形态及影响因素——以许昌清潩河为例. 中国环境科学, 2014, 34(3): 720-726.]

[24] Zhao YY, Yan MC eds. Geochemistry of immersed soil in shallow seas in China. Beijing: Science Press, 1994: $179-200$. [赵一阳, 漂明才. 中国浅海浸没土壤地球化学. 北京: 科学出版社, 1994: 179-200.] 
[25] Wang GQ, Zhu Z, Zhang S. Nitrogen forms in the surface sediment of Haizhou Bay and their ecological significance. Acta Scientiae Circumstantiae, 2016, 36(2): 450-457. [王功芹, 朱珠, 张硕. 海州湾表层沉积物中氮的赋存形态及其生 态意义. 环境科学学报, 2016, 36(2) : 450-457.]

[26] Shen HY, Zhang MM, Ni ZK et al. Distribution of transferable nitrogen in poyang lake sediments and its response to the variation of river-lake relationship. Environmental Science, 2015, 35(1):87-93. [ 沈洪艳, 张绵绵, 倪兆奎等. 鄱阳湖沉 积物可转化态氮分布特征及其对江湖关系变化的响应. 环境科学, 2015, 35(1): 87-93.]

[27] Jin ZF, Gong JL, Shi YL et al. Nitrate source identification and nitrification-denitrification at the sediment-water interface. Environmental Science, 2017, 38(4) : 1423-1430. [ 金赞芳, 龚嘉临, 施伊丽等. 沉积物-水界面氮的源解析和硝化反 硝化. 环境科学, 2017, 38(4) : 1423-1430.]

[28] He JZ, Zhang LM. Advances in ammonia-oxidizing microoeranisms and global nitrogen cycle. Acta Ecologica Sinica, 2009, 29(1): 406-415. [ 贺纪正, 张丽梅. 氨氧化微生物生态学与氮循环研究进展. 生态学报, 2009, 29(1) : 406-415.]

[29] Zhu ZJ, Chen JA, Zeng Y. Paleotemperature variations at Lake Caohai, southwestern China, during the past 500 years: Evidence from combined $\delta^{18} \mathrm{O}$ analysis of cellulose and carbonates. Science China: Earth Sciences, 2014, 44(2): 250258. [ 朱正杰, 陈敬安, 曾艳. 草海地区过去 500 年来古温度重建: 来自沉积物纤维素结合碳酸盐氧同位素的证据. 中国科学: 地球科学, $2014, \mathbf{4 4}(2): 250-258$. ]

[30] Wang SR, Jin XC, Jiao LX. Distribution of transferable nitrogen in different grain size from the different trophic level lake sediments. Research of Environmental Sciences, 2007, 20(3): 52-57. [王圣瑞, 金相灿, 焦立新. 不同污染程度湖泊沉 积物中不同粒级可转化态氮分布. 环境科学研究, 2007, 20(3) : 52-57.] 